\title{
Conference Paper \\ Optical pH Detection with U-Shaped Fiber-Optic Probes and Absorption Transducers
}

\author{
Jakub Zajíc, ${ }^{1}$ Lenka Traplová, ${ }^{1}$ Vlastimil Matějec, ${ }^{2}$ Marie Pospíšilová, ${ }^{1}$ and Ivo Bartoň ${ }^{2}$ \\ ${ }^{1}$ Faculty of Biomedical Engineering, Czech Technical University in Prague, Kladno 2, Czech Republic \\ ${ }^{2}$ Institute of Photonics and Electronics AS CR, v.v.i., Chaberská 57, 18251 Praha 8, Czech Republic \\ Correspondence should be addressed to Jakub Zajíc; jakub.zajic@hotmail.com
}

Received 12 December 2014; Accepted 18 February 2015

Academic Editor: José B. Quintana

This Conference Paper is based on a presentation given by Jakub Zajíc at "Meeting on Materials and Their Applications for Devices and Sensors 2014" held from 5 November 2014 to 7 November 2014 in Mahdia, Tunisia.

Copyright ( 2015 Jakub Zajíc et al. This is an open access article distributed under the Creative Commons Attribution License, which permits unrestricted use, distribution, and reproduction in any medium, provided the original work is properly cited.

In medicine knowledge of $\mathrm{pH}$ values can provide us with information not only about the patients' status but also about physiological processes in the patient's body. Measurements of $\mathrm{pH}$ in small-sample volumes and online $\mathrm{pH}$ monitoring in vivo can be employed to obtain such information. For such measurements we have developed and investigated U-shaped fiber-optic probes with immobilized $\mathrm{pH}$ indicators in this paper. U-shaped probes with a diameter of about $2 \mathrm{~mm}$ were prepared. Three different $\mathrm{pH}$ indicators, methyl red, methyl orange, and bromothymol blue, were immobilized in two types of matrices, namely, porous silica (PS) and ethylcellulose (EC), and applied on the U-shaped probes. Changes in spectra of transmitted power were measured and calibration curves were determined from these spectra. It has been found that a working $\mathrm{pH}$ range of prepared probes was from 3.1 to 7.6. The maximum sensitivity was about $0.11 / \mathrm{pH}$ unit. Effects of structural relaxations of detection layers and indicator leaching observed in experiments are discussed.

\section{Introduction}

Measurements of $\mathrm{pH}$ are broadly employed in industry, agriculture, biology, or medicine. In medicine $\mathrm{pH}$ of various body fluids such as urine, blood, gastric acid, or saliva is measured. Values of $\mathrm{pH}$ within or out of normal physiological $\mathrm{pH}$ ranges typical for these body fluids (e.g., from 7.35 to 7.45 for blood) can give us information about a patient's medical status. A number of medical studies have been published which were related, for example, to the monitoring of esophageal $\mathrm{pH}$ [1], fetal $\mathrm{pH}$ monitoring [2], and venous and arterial blood $\mathrm{pH}$ monitoring [3].

In order to measure $\mathrm{pH}$, different sensors including electrical and optical ones are used [4]. So far most of the investigated and developed optical $\mathrm{pH}$ sensors employ absorption or fluorescence $\mathrm{pH}$ indicators [5] which interact with protons and change their optical properties due to such interactions [4]. A refractive-index based $\mathrm{pH}$ sensor has also been developed [6]. Polymeric or sol-gel detection membranes have been used for the immobilization of $\mathrm{pH}$ transducers or for proton and other ion adsorptions $[4,6,7]$.

Different sensing platforms of optical $\mathrm{pH}$ sensors have been investigated [4], such as planar sensors or fiber-optic sensors. Fiber-optic pH sensors are usually based on the evanescent-wave and reflection principles [4, 8-11]. Mainly reflection-based sensors have been commercialized [4]. Such sensors have been used in medicine [11], for example, for monitoring gastroesophageal reflux, because they are small and can be easily inserted into medical catheters.

Several approaches have been tested in order to increase the response of evanescent-wave fiber-optic $\mathrm{pH}$ sensing probes [12-14]. They include mode filtering [12], etching a multimode sensing fiber to open the access to the corecladding boundary [13], and bending the probe fiber to a $\mathrm{U}$ shape [14-16]. U-shaped evanescent-wave probes offer us several advantages over straight ones such as enhanced sensitivity and small dimensions which could be used in $\mathrm{pH}$ sensors for medicine [14]. However, only one paper [14] 
presents results determined with absorption $\mathrm{pH}$ transducers immobilized in a detection membrane.

This paper presents results of the investigation of $\mathrm{U}$ shaped probes provided with three different absorption $\mathrm{pH}$ indicators, namely, methyl orange, methyl red, and bromothymol blue. The indicators were immobilized in the probe cladding by using matrices of porous silica or ethylcellulose. Spectral responses and calibration curves of the probes are reported.

\section{Experiment}

2.1. Fabrication of U-Shaped Probes. U-shaped sensing elements were prepared from segments of polymer clad silica (PCS) fibers with silica core diameters of $400 \mu \mathrm{m}$ and lengths of about $50 \mathrm{~cm}$. The fibers were prepared at the Institute of Photonics and Electronics. In each preparation the original optical cladding of dimethylpolysiloxane polymer was removed from the central part of the segment in a length of about $5 \mathrm{~cm}$. For this removal the segment was immersed in an aqueous solution containing hydrofluoric acid for about five minutes and the swelled cladding was mechanically stripped. The bare silica core was shortly dipped into a solution composed of hydrofluoric and nitric acids and rinsed with water. Then the center of this bare part was carefully heated in an oxyhydrogen burner flame and manually bent to an arch with a diameter of about $2 \mathrm{~mm}$. In order to fix arch dimensions, the segment arms coated with the polymer cladding were inserted into a small glass tube and glued in it using a silicone adhesive. Then the bent part was dipped in the solution of hydrofluoric and nitric acids, rinsed in water, and dried in air. Detection layers containing $\mathrm{pH}$ indicators were applied on the bare parts of such detection elements.

2.2. Preparation of Detection Layers. Three $\mathrm{pH}$ indicators, namely, methyl orange (a pH detection range of 3.1-4.4 in aqueous solutions), methyl red (a $\mathrm{pH}$ range of 4.4-6.2 in aqueous solutions), and bromothymol blue (a $\mathrm{pH}$ range of 6-7.6 in aqueous solutions), have been investigated. Powders of the indicators were purchased from Sigma-Aldrich, Czech Republic. These indicators were immobilized in matrices prepared from alkoxide, tetramethylorthosilicate (TMOS), or polymer and ethylcellulose (EC). Chemicals were purchased from Sigma-Aldrich, Czech Republic.

Alkoxide-based detection layers were fabricated by the sol-gel method from input alkoxide sols. In experiments a starting sol was prepared from TMOS $(C=1 \mathrm{~mol} / \mathrm{L})$, ethanol as a solvent, nitric acid as a catalyst and water (water/alkoxide ratio $=1.5$ ) at first. The sol was aged at $70^{\circ} \mathrm{C}$ for 1 hour while being stirred. The composition of the sol was selected on the basis of results reported elsewhere [17, 18]. Each input sol was prepared by dissolving a particular indicator in the starting sol. On the basis of bulk absorption spectra measurements, concentrations of $0.1,0.5$, and $0.5 \mathrm{~g} / \mathrm{L}$ were used for methyl red, methyl orange, and bromothymol blue, respectively. The input sols were applied onto the $U$-shaped elements by dip-coating technique (withdrawing speed of $10 \mathrm{~cm} / \mathrm{min}$ ). Applied gel layers were dried at $90^{\circ} \mathrm{C}$ for 24

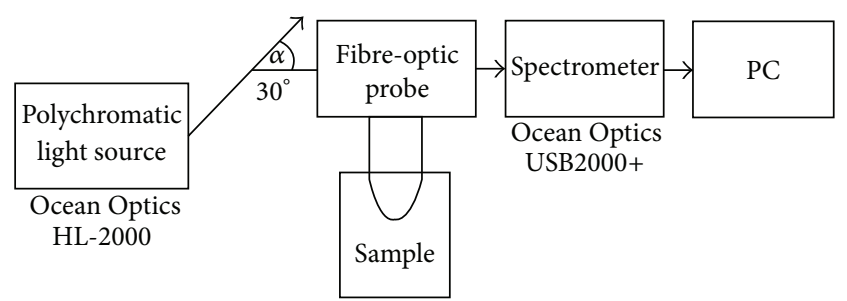

FIgURE 1: Scheme of the experimental setup for characterization of U-shaped probes.

hours. A thickness of about $0.3 \mu \mathrm{m}$ and a refractive index of about 1.42 can be estimated for such detection layers on the basis of previous experiments.

Ethylcellulose detection layers were prepared by using an approach reported elsewhere [19]. Two input solutions A and $\mathrm{B}$ were prepared at first. Solution A contained one of the particular $\mathrm{pH}$ indicators at a concentration of $0.6 \mathrm{~g} / \mathrm{L}$, tetraoctylammonium hydroxide (TOAH), and methanol. Solution B contained ethylcellulose $15 \mathrm{wgt} . \%$ in $80 \mathrm{~mL}$ of toluene and $20 \mathrm{~mL}$ of ethanol. A final solution used for coating was mixed from $1 \mathrm{~mL}$ of solution $\mathrm{A}, 10 \mathrm{~g}$ of solution $\mathrm{B}, \mathrm{TOAH}$, and tributyl phosphate. The final solution was applied on $\mathrm{U}$-shaped elements by dip-coating technique (withdrawing speed of $10 \mathrm{~cm} / \mathrm{min}$ ) and dried at $80^{\circ} \mathrm{C}$ for 1 hour. For these detection layers a thickness of about $3 \mu \mathrm{m}$ and a refractive index of about 1.49 can be estimated from measurements on glass slides.

2.3. Absorption Spectra of Indicator Solutions. Absorption spectra of the indicators in different aqueous solutions were measured in a range of $200-1100 \mathrm{~nm}$ and used as a reference to those determined by using U-shaped detection probes. For such purpose a PerkinElmer Lambda EZ210 spectrometer and a cuvette with a path of $1 \mathrm{~cm}$ were used. Test solutions of hydrochloric acid with concentrations of $10^{-1}-10^{-4} \mathrm{~mol} / \mathrm{L}$, acetic buffer solutions mixed of acetic acid and sodium acetate, and Sorensen buffer solutions mixed of potassium and sodium phosphates were used. Values of $\mathrm{pH}$ of such solutions were determined electrochemically by using a $\mathrm{pH}$ meter Jenway 3306. The indicators were dissolved in the measured solutions in a concentration of $0.05 \mathrm{~g} / \mathrm{L}$.

2.4. Characterization of U-Shaped Detection Probes. Transmission spectra of prepared U-shaped detection probes were measured by using a setup schematically shown in Figure 1. The setup consisted of a halogen lamp Ocean Optics HL 2000 as a light source and an Ocean Optics USB 650 diode array spectrometer as a detector. An integration time of $100 \mathrm{~ms}$ and averaging of three spectra allowed us to measure the output power with an accuracy of about 30 arb. units. In experiments tested fibers were joined to the detector via an FC connector. The input part of the fiber was fixed in a holder that enabled directing light beams from the source into fibers under beam inclination. Such an arrangement was used to further increase the detection sensitivity. Angles of inclination of about $30^{\circ}$ were used. Tested U-shaped elements were immersed in 


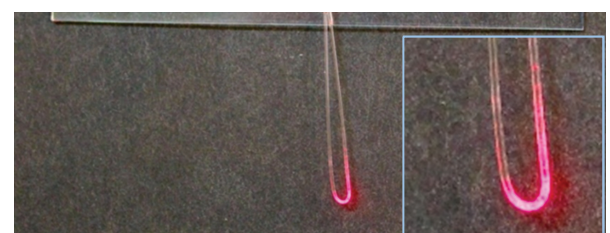

Figure 2: Photo of a U-shaped fiber element; onset: details of the element arc.

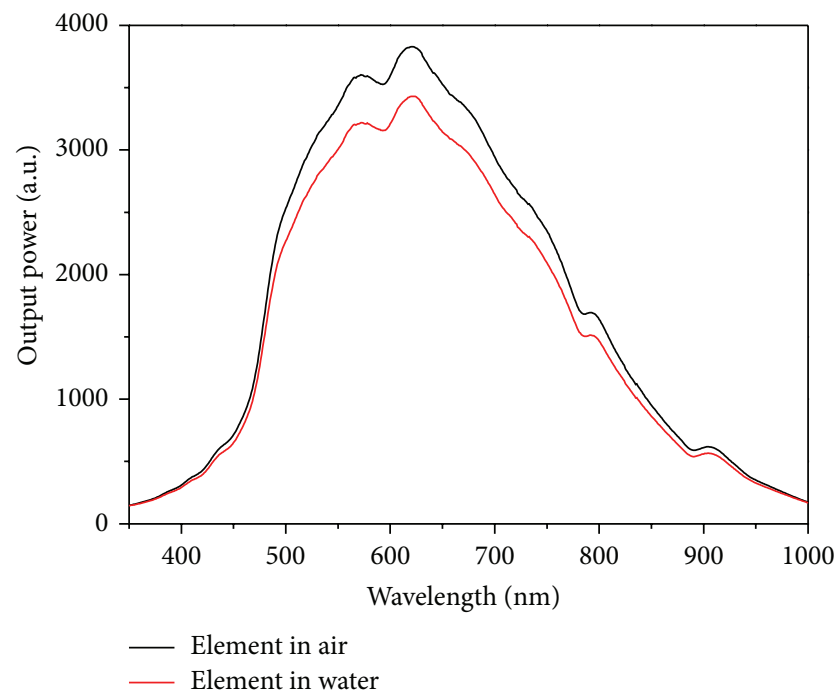

FIGURE 3: Output powers of a U-shape fiber without a detection layer in air and in water.

the test solutions with different $\mathrm{pH}$ and spectral output powers from tested fibers were measured in a range of $350-$ $1100 \mathrm{~nm}$.

\section{Results and Discussion}

A photo of one prepared U-shaped element is shown in Figure 2. Light from a red-laser pointer was directed into the right arm of the element to highlight the probe.

Figure 3 shows spectra of output power from a U-shaped element without any detection layer. A decrease of the output power caused by immersing the element in water can be explained by a refractive-index change from air (a value of about 1) to water (a refractive index of about 1.33).

Bulk absorption spectra of the tested indicators measured for different $\mathrm{pH}$ values are shown in Figures 4(a)-4(c). All the spectra show absorption bands which can be attributed to basic and acidic forms of the indicators. Thus, for methyl red one can conclude from Figure 4(a) that the acidic indicator form, that exists at lower $\mathrm{pH}$ values, absorbs light at about $550 \mathrm{~nm}$ while the basic one, that is present at at higher $\mathrm{pH}$ values, absorbs light at about $430 \mathrm{~nm}$. In the case of methyl orange the band of the acidic form is centered at about $520 \mathrm{~nm}$ and that of the basic form at about $450 \mathrm{~nm}$ (see Figure 4(b)). The indicator bromothymol blue has the absorption band of its basic form centered at about $630 \mathrm{~nm}$ and the acidic form absorbs light at about $450 \mathrm{~nm}$ as one can see from Figure 4(c).

Spectra of output power measured for different $\mathrm{pH}$ with a $\mathrm{U}$-shaped element coated with the detection layer of methyl red in ethylcellulose are shown in Figure 5(a). The element was immersed in solutions of hydrochloric acid and in acetic buffer solutions. By comparing curves in Figure 4(a) with those in Figure 5(a) one can conclude that there are power changes in a spectral range from about 600 to $1000 \mathrm{~nm}$ which cannot be attributed to spectral changes of methyl red. They can be explained by relaxation changes of the ethylcellulose matrix, i.e. by changes of its refractive index. Spectral changes related directly to methyl red changes can be identified in a range of $480-600 \mathrm{~nm}$. Taking values of the output power at a wavelength of $590 \mathrm{~nm}$ and plotting them against the $\mathrm{pH}$ values, measured electrochemically, calibration curves in Figure 5(b) can be drawn with a reference of an ethylcellulose layer without methyl red. Such curves were obtained by fitting experimental data with a sigmoidal Boltzmann curve [20]. The curves in Figure 5(b) show that methyl red in the ethylcellulose matrix can be used for $\mathrm{pH}$ detection in a $\mathrm{pH}$ range of 3-5.5. The different calibration curves for different measurements in Figure 5(b) can be explained by relaxation changes in the layer. Some leaching of the indicator can be concluded from slightly different slopes of the calibration curves for different measurements. A detection sensitivity of about $0.01-0.021 / \mathrm{pH}$ unit can be determined from Figure 5(b).

Experimental results determined with a U-shape probe coated with the layer of methyl red in porous silica are shown in Figures 6(a) and 6(b). The probe was immersed in the acetate buffer solutions. In this case a different evaluation approach was used that consists in using output power measured with the layer in water as the reference and in normalizing the resulting spectra to the methyl red isosbestic point at $480 \mathrm{~nm}$. It is expected that such an approach could suppress relaxation changes. Difference spectra in Figure 6(a) show two bands of methyl red, one at about $430 \mathrm{~nm}$ and the other at about $570 \mathrm{~nm}$. On the basis of the spectra in Figure 4(a), in Figure 6(a) the band at $430 \mathrm{~nm}$ can be attributed to the methyl red basic form and that at $570 \mathrm{~nm}$ to the acidic indicator form.

Taking values of the absorbance at $560 \mathrm{~nm}$ from Figure 6(a) and plotting them against $\mathrm{pH}$ values measured electrochemically, the calibration curves in Figure 6(b) were drawn. They show that the probe has a linear response in a $\mathrm{pH}$ range from 3.8 to 6.5 . A sensitivity of about $0.031 / \mathrm{pH}$ unit can be estimated from the calibration curves.

Spectra of output power from a U-shaped element coated with the detection layer consisting of bromothymol blue in ethylcellulose are shown in Figure 7(a). Sorensen buffer solutions were used for the probe tests. In this case a power dip centered at about $630 \mathrm{~nm}$ can be attributed to the basic form of bromothymol blue. Taking output power values at $630 \mathrm{~nm}$ from Figure 7(a), calibration curves in Figure 7(b) can be drawn with a reference of an EC layer without bromothymol blue. The curves in Figure 7(b) show that bromothymol blue in the EC matrix can be used for $\mathrm{pH}$ detection from $\mathrm{pH}=6.2$ to $\mathrm{pH}=8$. A maximum detection 


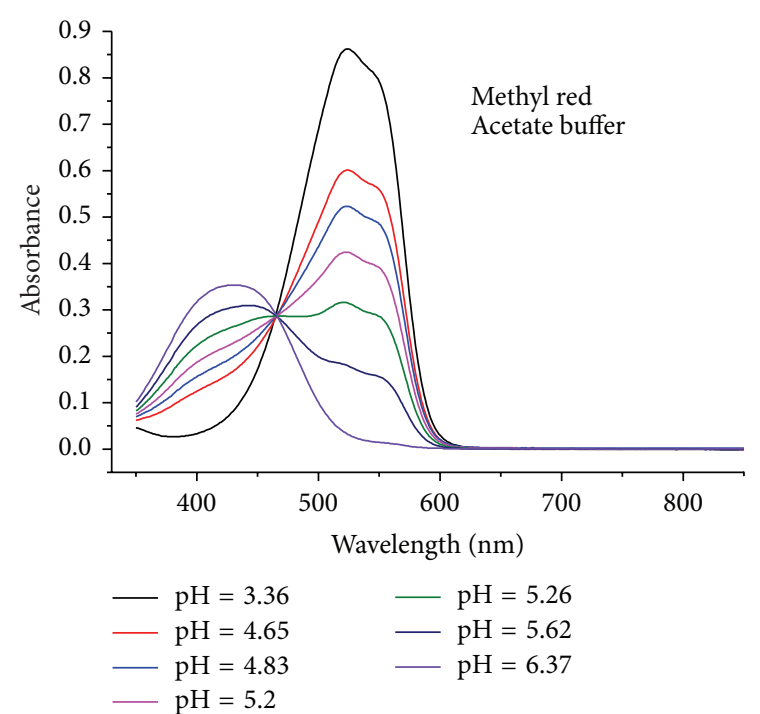

(a)

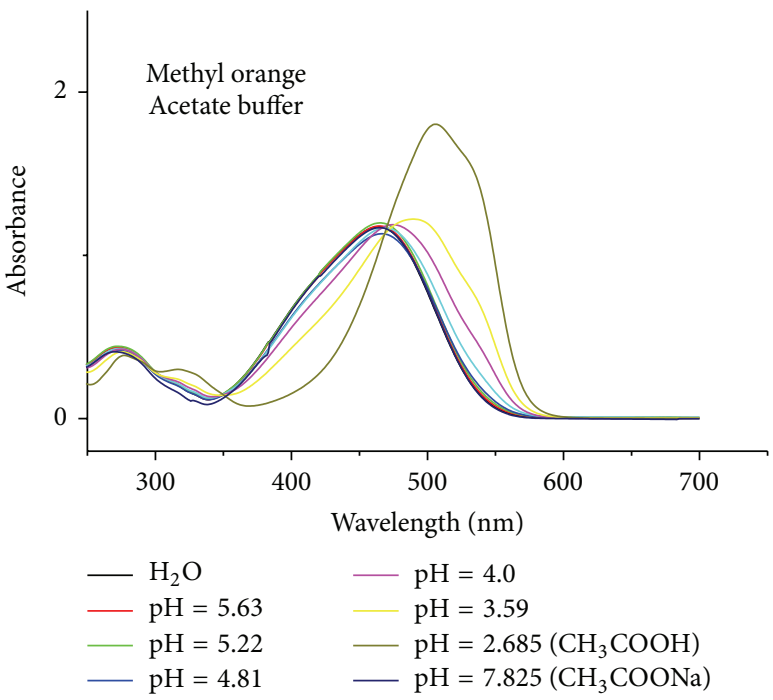

(b)

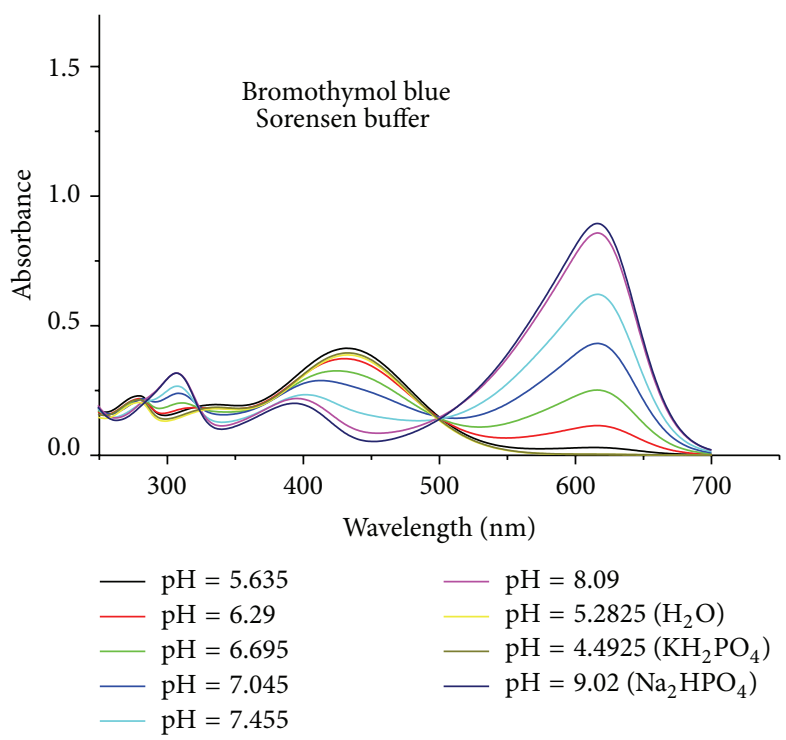

(c)

FIGURE 4: Bulk absorption spectra of indicator solutions at different pH; (a) methyl red, (b) methyl orange, and (c) bromothymol blue.

sensitivity of about $0.151 / \mathrm{pH}$ unit can be determined from Figure 7(b) (first measurement). However, from Figure 7(b) it is also evident that the element response and sensitivity substantially dropped down when the measurement was repeated (cf. 1st and 2nd measurements). Such results can be explained by leaching of the indicator from the layer. The swelling of the detection layer in Sorensen buffer solutions also takes place.

Spectra of output power measured with a U-shaped probe coated by the detection layer of bromothymol blue in porous silica immersed in different Sorensen buffer solutions were also measured. They were similar to those shown in Figure 7(a); however, a spectral dip attributed to bromothymol blue was smaller. Calibration curves determined from the measured spectra are shown in Figure 8 for a wavelength of $655 \mathrm{~nm}$ and a reference of an EC layer without bromothymol blue. These curves show that the probe has a linear response in a $\mathrm{pH}$ range from 6.6 to 7.5 . The sensitivity of about $0.041 / \mathrm{pH}$ unit can be estimated from the calibration curve for 1st measurement that decreases to about $0.0051 / \mathrm{pH}$ unit for 2 nd measurement. The indicator leaching and relaxation changes in the detection layer can explain differences between the calibration curves for 1st and 2nd measurements.

A set of experiments was made with a straight PCS fiber segment coated with a detection layer of bromothymol blue in ethylcellulose prepared at the same condition as that on the U-shaped probe. A maximum sensitivity of about 0.007 $1 / \mathrm{pH}$ unit was determined from measured response curves. This value shows that bending a detection probe to a $U$ shape is related to a sensitivity increase. 


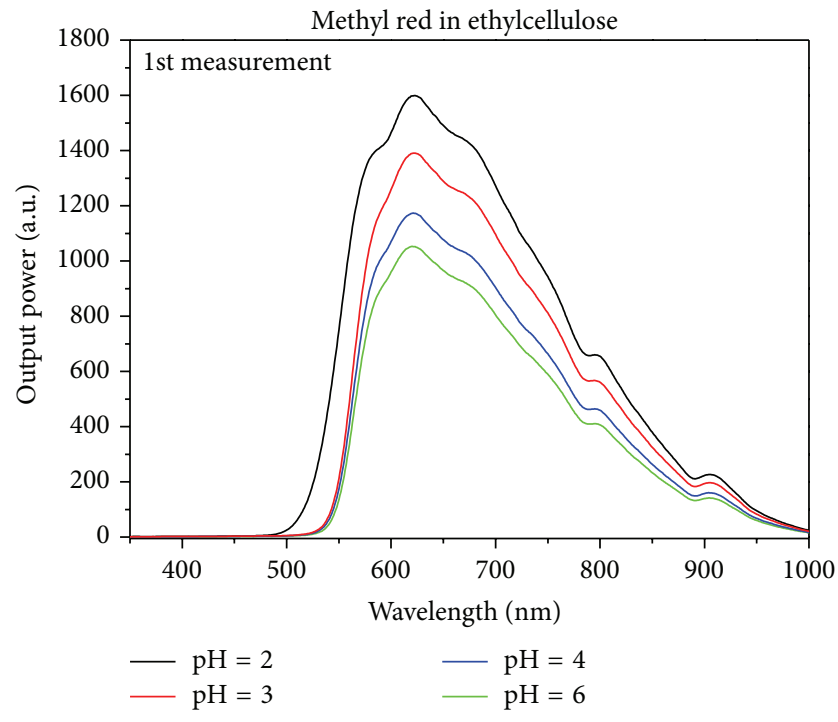

(a)

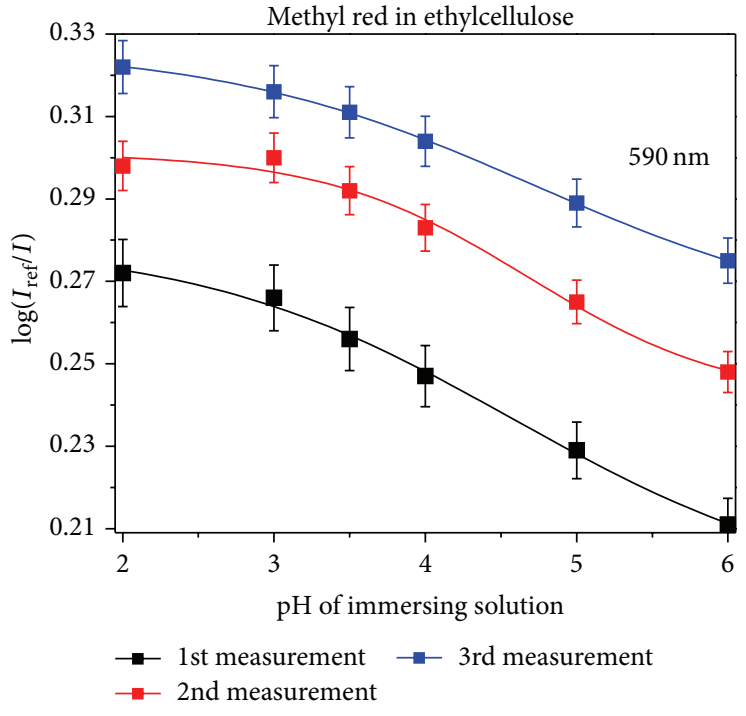

(b)

FIGURE 5: (a) Output power from U-shaped probe coated by detection layer of methyl red in ethylcellulose; (b) calibration curves of the $\mathrm{U}$-shaped probe for repeated measurements.

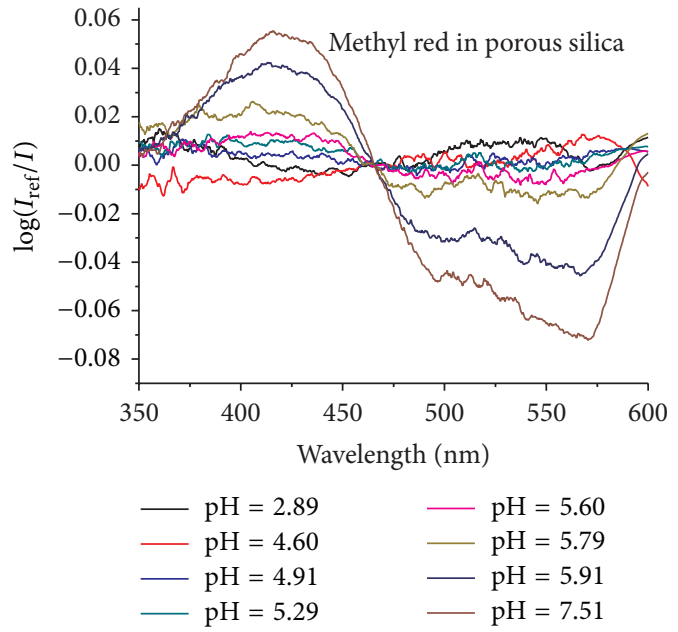

(a)

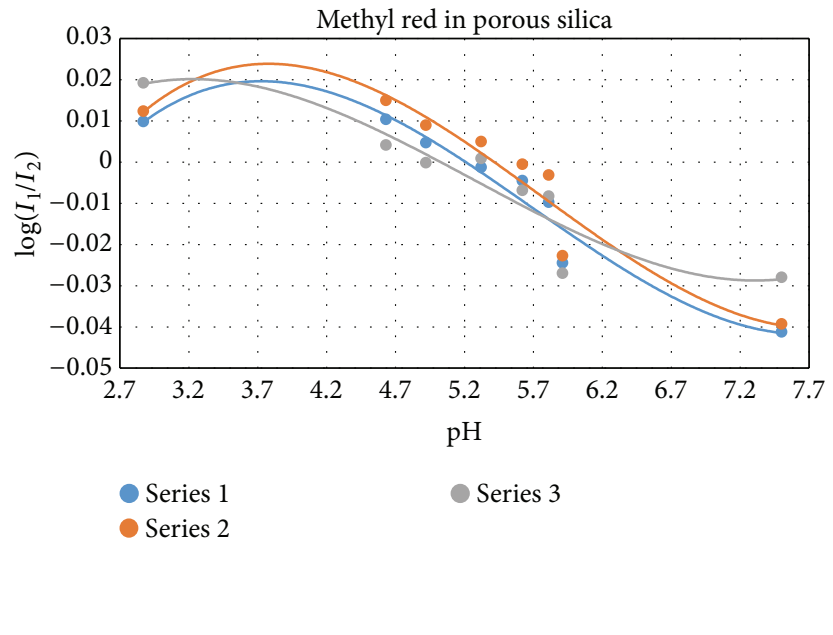

(b)

FIGURE 6: (a) Normalized absorption spectra measured on a layer of methyl red in porous silica applied on a U-shaped probe; (b) calibration curves of the coated U-shaped probe at $560 \mathrm{~nm}$.

Spectra of output power from a U-shaped element coated with the detection layer of methyl orange in ethylcellulose for different $\mathrm{pH}$ values are shown in Figure 9(a). Responses of probes with this indicator were tested by immersing the probe in solutions of hydrochloric acid. By taking into account the curves in Figure 4(b) one can conclude that spectral changes related directly to methyl orange changes are in a range of $400-600 \mathrm{~nm}$ and that there are power changes related to the layer relaxation at longer wavelengths.

Taking values of output power at a wavelength of $590 \mathrm{~nm}$, calibration curves in Figure 9(b) can be drawn with a reference of an ethylcellulose layer without methyl orange. The curves in Figure 9(b) show that methyl orange in the ethylcellulose matrix can be used for $\mathrm{pH}$ detection in a $\mathrm{pH}$ range of 3-4.5. Similarly as with the previous $\mathrm{pH}$ indicators the element response was changed when experiments were repeated due to swelling of the detection layer. In this case the leaching of the indicator from the detection layer is not probably strong because the curve slopes in Figure 9(b) do not differ much for 1st and 2nd measurements. The sensitivity of about 0.005 1/pH unit can be determined from Figure 9(b).

Similar spectra of output power as those in Figure 9(a) were measured with a U-shaped probe coated by the detection layer of methyl orange in porous silica. Calibration curves at $540 \mathrm{~nm}$ determined from such spectra are shown in Figure 10 with a reference of a porous silica layer without 


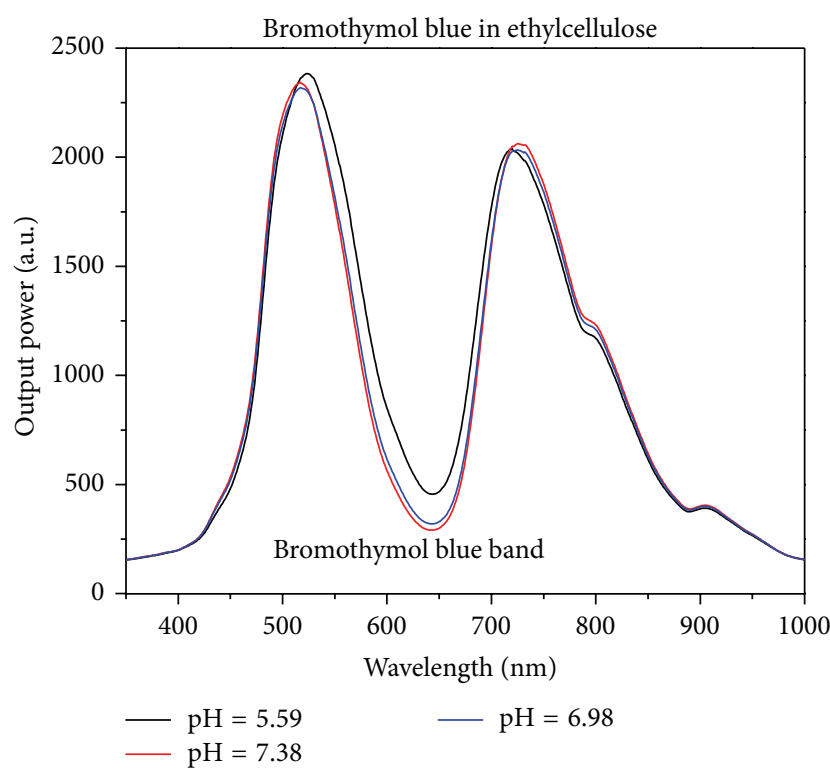

(a)

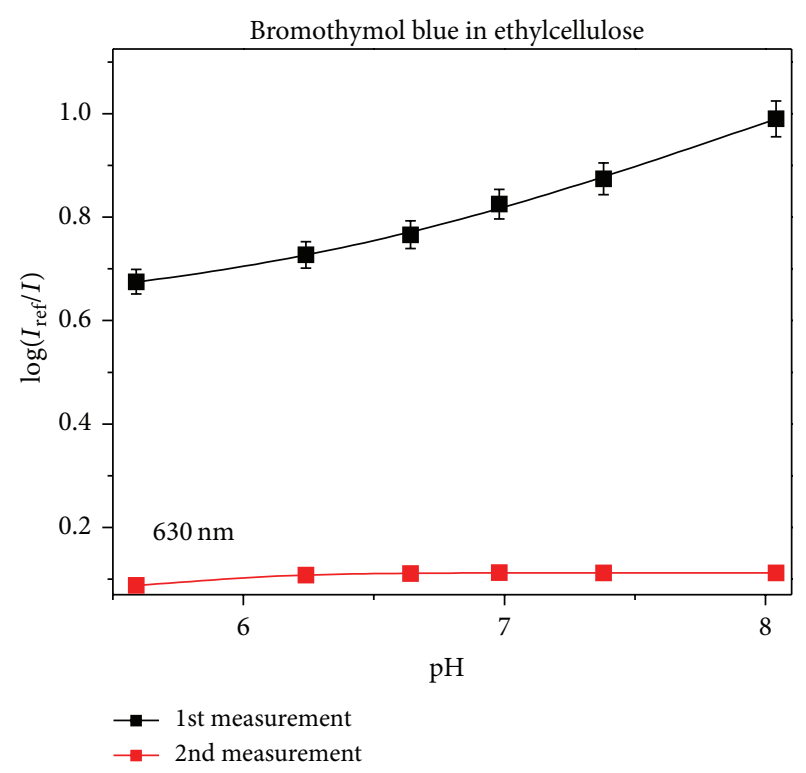

(b)

FIGURE 7: (a) Spectral output power from a U-shaped element provided with a layer of bromothymol blue in ethylcellulose; (b) calibration curves of the U-shaped probe for repeated measurements at $630 \mathrm{~nm}$.

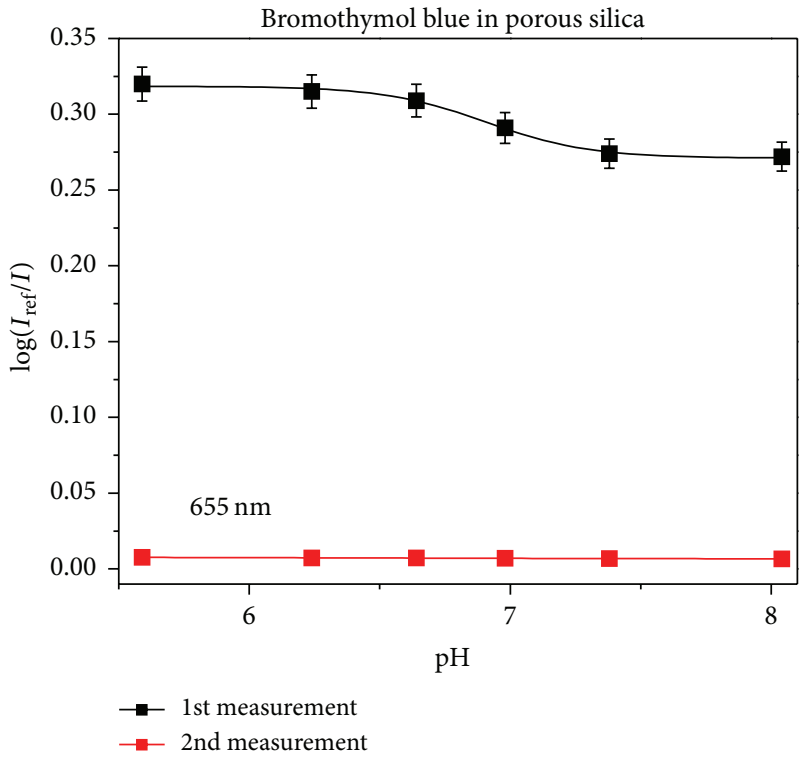

FIGURE 8: Calibration curves of a U-shaped probe coated with detection layer of bromothymol blue in porous silica for repeated measurements at $655 \mathrm{~nm}$.

methyl orange. The sensitivity of about $0.031 / \mathrm{pH}$ unit can be estimated from the calibration curve for a $\mathrm{pH}$ range from 3.2 to 4.5 (Figure 10, the black line). However, this sensitivity decreases to about $0.0151 / \mathrm{pH}$ unit when the calibration is repeated (see Figure 10, the red line).

As the used measurement setup did not allow us to do time-response measurements at a particular wavelength the time response of the probes could be only estimated from measured spectral responses. It has been found that when a U-shaped detection probe was immersed into a tested solution an output power changed quickly within approximately one minute. The output power changed much slowly after more than 5-10 min. Thus, a short immersion of the probes in testing solutions on a level of $1-3$ min was used in all experiments.

Experimental results discussed above show that Ushaped fiber-optic probes, fabricated from PCS optical fibers, can exhibit the sensitivity to $\mathrm{pH}$ provided that colorimetric $\mathrm{pH}$ indicators are applied onto their bent part. By comparing results of the measurements on bulk solutions (see Figure 4) with those made by the U-shaped probes (Figures 5-9) one can see that the probes exhibit lower responses to $\mathrm{pH}$ changes. The detection sensitivity also decreases from about $0.3-0.4$ $1 / \mathrm{pH}$ unit to $0.005-0.151 / \mathrm{pH}$ unit (for first measurements). This sensitivity decrease can be explained by a ratio of power in the evanescent field of fiber-optic sensors on a level from 0.005 to 0.05 . In the case of the U-shaped probes it has also been found that such probes are sensitive to refractiveindex changes related to relaxation changes (swelling) of detection layers. Such relaxation changes induce baseline changes of measured spectra and consequently influence the spectral response of probes caused by $\mathrm{pH}$ indicators. It has also been observed that some colorimetric indicators such as bromothymol blue can leach out from detection layers of ethylcellulose in aqueous solutions which decreases the detection sensitivity.

\section{Conclusions}

It has been found that U-shaped fiber-optic probes coated with three types of absorption $\mathrm{pH}$ indicators, namely, methyl 


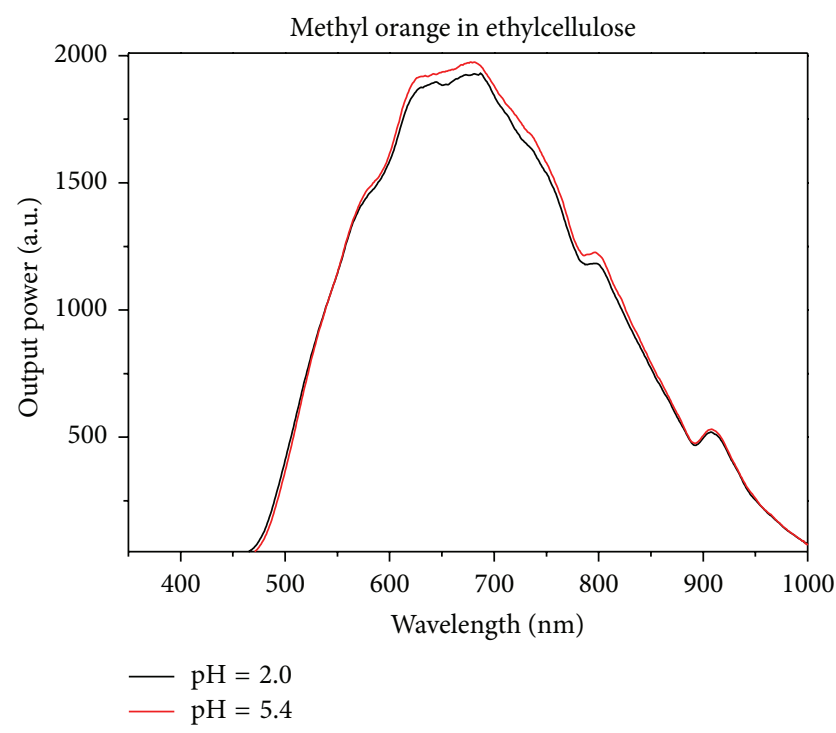

(a)

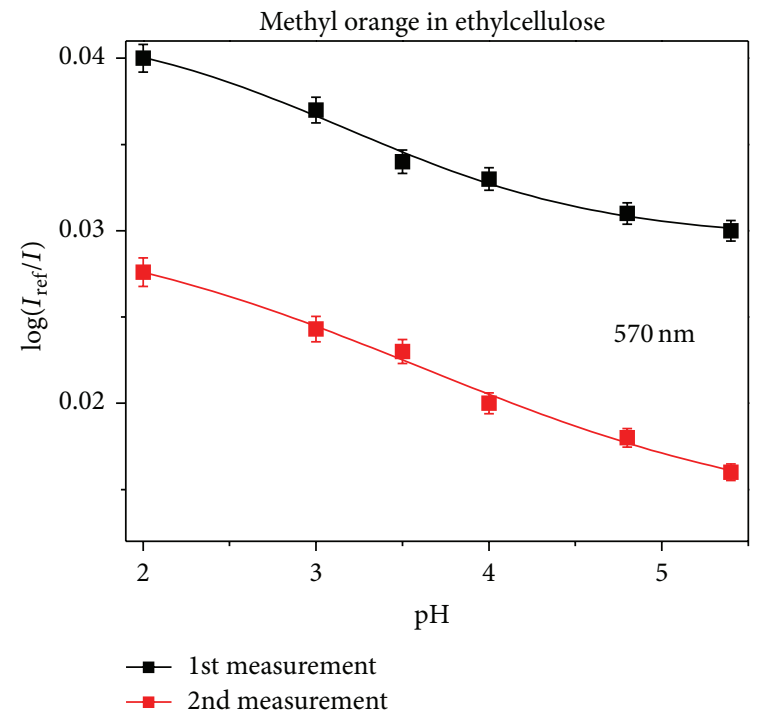

(b)

FIGURE 9: (a) Spectra of output power from a U-shaped element provided with a layer of methyl orange in ethylcellulose; (b) calibration curves of the U-shaped probe for repeated measurements at $590 \mathrm{~nm}$.

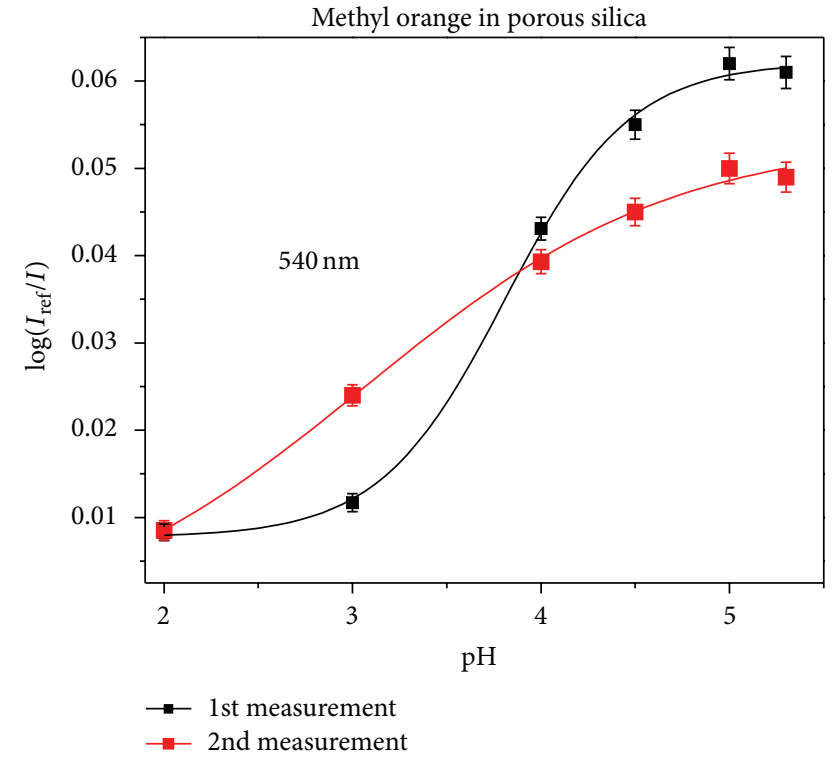

Figure 10: Calibration curves of the U-shaped probe for repeated measurements at $540 \mathrm{~nm}$, methyl orange in porous silica.

orange, methyl red, and bromothymol blue, can be used for $\mathrm{pH}$ detection in a $\mathrm{pH}$ range from about 3 to 7.6 in aqueous solutions. It has been proved that the indicators can be immobilized in matrices of porous silica or ethylcellulose. These matrices, however, exhibit some relaxation changes which complicate the interpretation of measured experimental data. The approach has been developed that is based on normalizing sensor responses to those determined at isosbestic points of used indicators and which, to some extent, can suppress such relaxations. This approach needs to be further improved as well as the composition of matrices of detection layers. Bromothymol blue leaching has been observed which can decrease the detection sensitivity from $0.151 / \mathrm{pH}$ unit to about $0.02-0.031 / \mathrm{pH}$ unit when detection experiments are repeated. These effects will be further investigated. Such $\mathrm{U}$-shaped $\mathrm{pH}$ detection probes are expected to find use at $\mathrm{pH}$ measurements on small volumes of aqueous samples in medicine and biology.

\section{Conflict of Interests}

The authors declare that there is no conflict of interests regarding the publication of this paper.

\section{Acknowledgment}

This work was financially supported by the Project "BIOOPT-XUV Research Team Advancement" at the Faculty of Biomedical Engineering, CTU, Prague, no. MEYS ESF Project CZ.1.07/2.3.00/20.0092.

\section{References}

[1] R. Stewart, "Oesophageal pH monitoring," Springer, Irish Journal of Medical Science, vol. 160, p. 41, 1997.

[2] C. Picard and H. Ben-Ayed, "Continuous fetal pH monitoring," Archives of Gynecology, vol. 226, no. 1-2, pp. 157-161, 1978.

[3] C. Kirubakaran, J. E. J. Gnananayagam, and E. K. Sundaravalli, "Comparison of blood gas values in arterial and venous blood," The Indian Journal of Pediatrics, vol. 70, no. 10, pp. 781-785, 2003.

[4] D. Wencel, T. Abel, and C. McDonagh, "Optical chemical pH sensors," Analytical Chemistry, vol. 86, no. 1, pp. 15-29, 2014.

[5] I. Kasik, J. Mrazek, T. Martan et al., "Fiber-optic pH detection in small volumes of biosamples," Analytical and Bioanalytical Chemistry, vol. 398, no. 5, pp. 1883-1889, 2010. 
[6] J. Rayss and G. Sudolski, "Ion adsorption in the porous sol-gel silica layer in the fibre optic $\mathrm{pH}$ sensor," Sensors and Actuators, B: Chemical, vol. 87, no. 3, pp. 397-405, 2002.

[7] O. Korostynska, K. Arshak, E. Gill, and A. Arshak, "Review on state-of-the-art in polymer based pH sensors," Sensors, vol. 7, no. 12, pp. 3027-3042, 2007.

[8] A. J. Rodríguez, C. R. Zamarreño, I. R. Matías, F. J. Arregui, R. F. D. Cruz, and D. A. May-Arrioja, "A fiber optic ammonia sensor using a universal pH indicator," Sensors, vol. 14, no. 3, pp. 40604073, 2014.

[9] Y. Xiong, Y. Huang, Z. Ye, and Y. Guan, "Flow injection smallvolume fiber-optic $\mathrm{pH}$ sensor based on evanescent wave excitation and fluorescence determination," Journal of Fluorescence, vol. 21, no. 3, pp. 1137-1142, 2011.

[10] A. B. Ganesh and T. K. Radhakrishnan, "Fiber-optic sensors for the estimation of $\mathrm{pH}$ within natural biofilms on metals," Sensors and Actuators, B: Chemical, vol. 123, no. 2, pp. 1107-1112, 2007.

[11] F. Baldini, A. N. Chester, J. Homola, and S. Martellucci, Eds., Optical Chemical Sensors, Springer, 2006.

[12] S. Wu, W. Cheng, Y. Qiu, Z. Li, S. Shuang, and C. Dong, "Fiber optic $\mathrm{pH}$ sensor based on mode-filtered light detection," Sensors and Actuators, B: Chemical, vol. 144, no. 1, pp. 255-259, 2010.

[13] S. Dong, M. Luo, G. Peng, and W. Cheng, "Broad range $\mathrm{pH}$ sensor based on sol-gel entrapped indicators on fibre optic," Sensors and Actuators B: Chemical, vol. 129, no. 1, pp. 94-98, 2008.

[14] B. D. Gupta and N. K. Sharma, "Fabrication and characterization of U-shaped fiber-optic $\mathrm{pH}$ probes," Sensors and Actuators B: Chemical, vol. 82, no. 1, pp. 89-93, 2002.

[15] P. K. Choudhury and T. Yoshino, "On the $\mathrm{pH}$ response of fiber optic evanescent field absorption sensor having a U-shaped probe: an experimental analysis," Optik, vol. 114, no. 1, pp. 13$18,2003$.

[16] F. Surre, W. B. Lyons, T. Sun et al., "U-bend fibre optic $\mathrm{pH}$ sensors using layer-by-layer electrostatic self-assembly technique," Journal of Physics: Conference Series, vol. 178, no. 1, Article ID 012046, 2009.

[17] T. M. Butler, B. D. MacCraith, and C. McDonagh, "Leaching in sol-gel-derived silica films for optical $\mathrm{pH}$ sensing," Journal of Non-Crystalline Solids, vol. 224, no. 3, pp. 249-258, 1998.

[18] B. D. MacCraith, C. M. McDonagh, G. O’Keeffe, A. K. McEvoy, T. Butler, and F. R. Sheridan, "Sol-gel coatings for optical chemical sensors and biosensors," Sensors and Actuators: B. Chemical, vol. 29, no. 1-3, pp. 51-57, 1995.

[19] A. Mills and Q. Chang, "Colorimetric polymer film sensors for dissolved carbon dioxide," Sensors and Actuators B: Chemical, vol. 21, no. 2, pp. 83-89, 1994.

[20] A. Song, S. Parus, and R. Kopelman, "High-performance fiber optic $\mathrm{pH}$ microsensors for practical physiological measurements using a dual-emission sensitive dye," Analytical Chemistry, vol. 69, no. 5, pp. 863-867, 1997. 

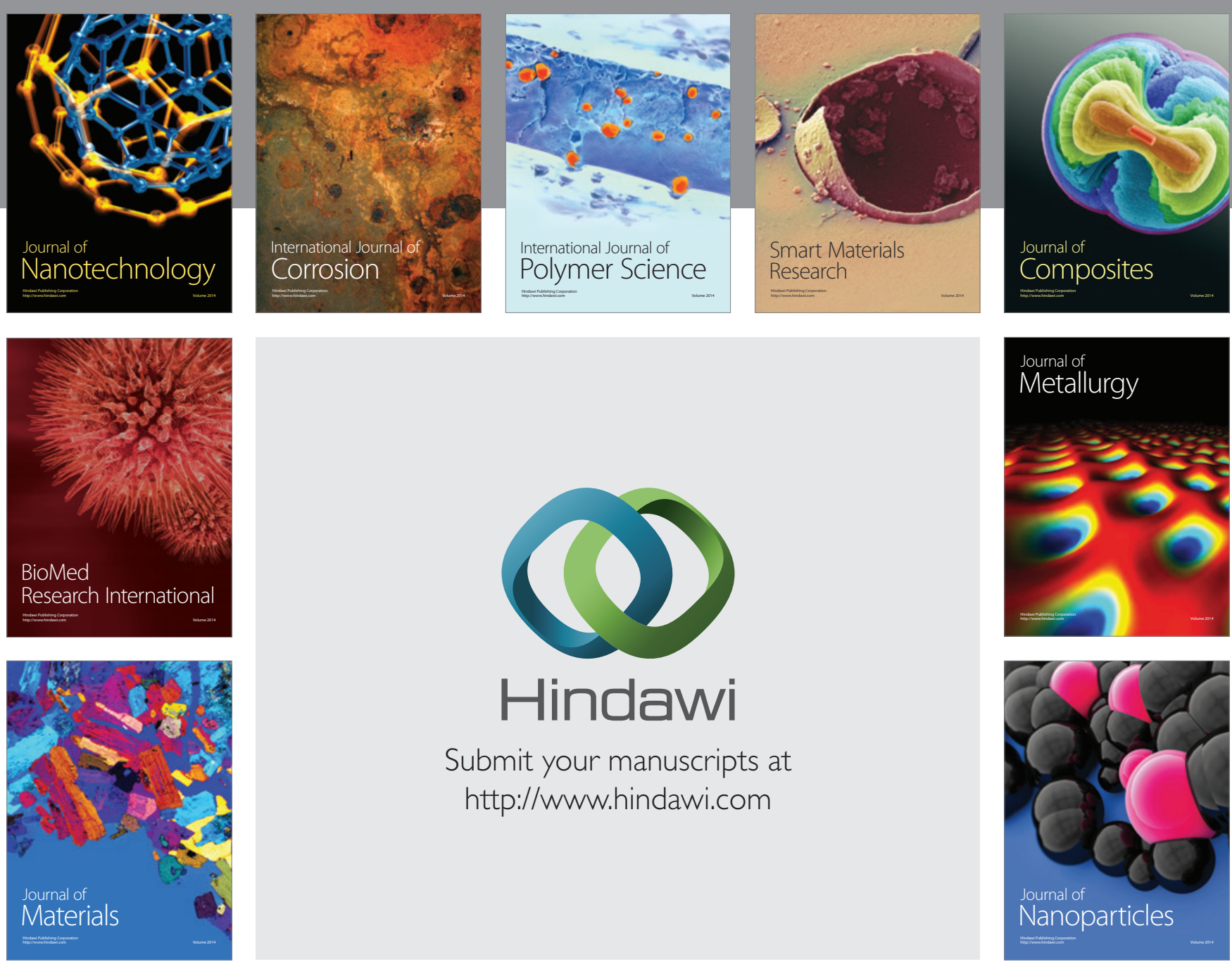

Submit your manuscripts at http://www.hindawi.com
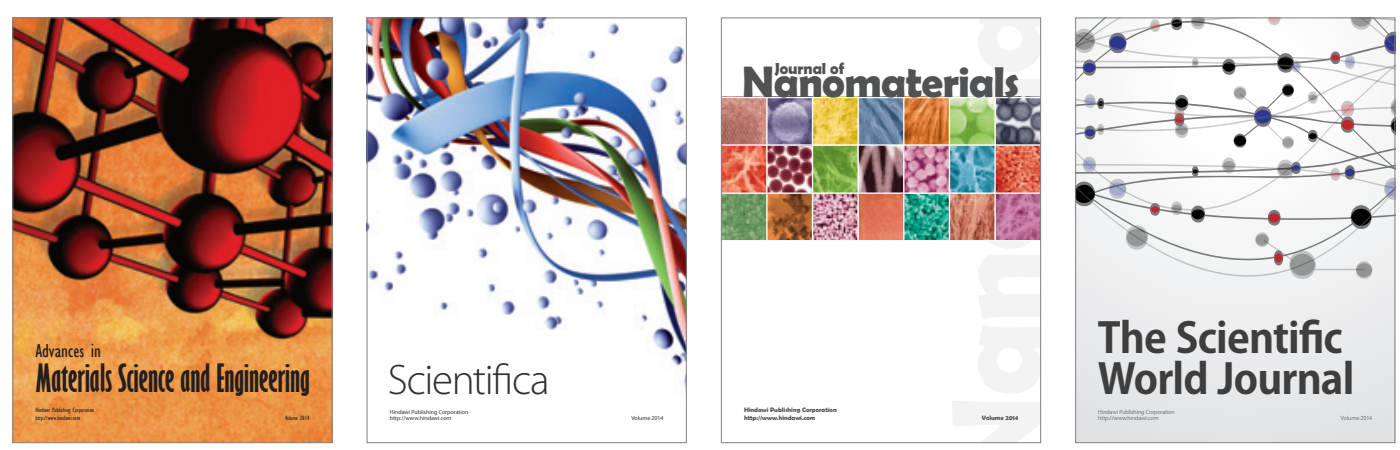

\section{The Scientific World Journal}
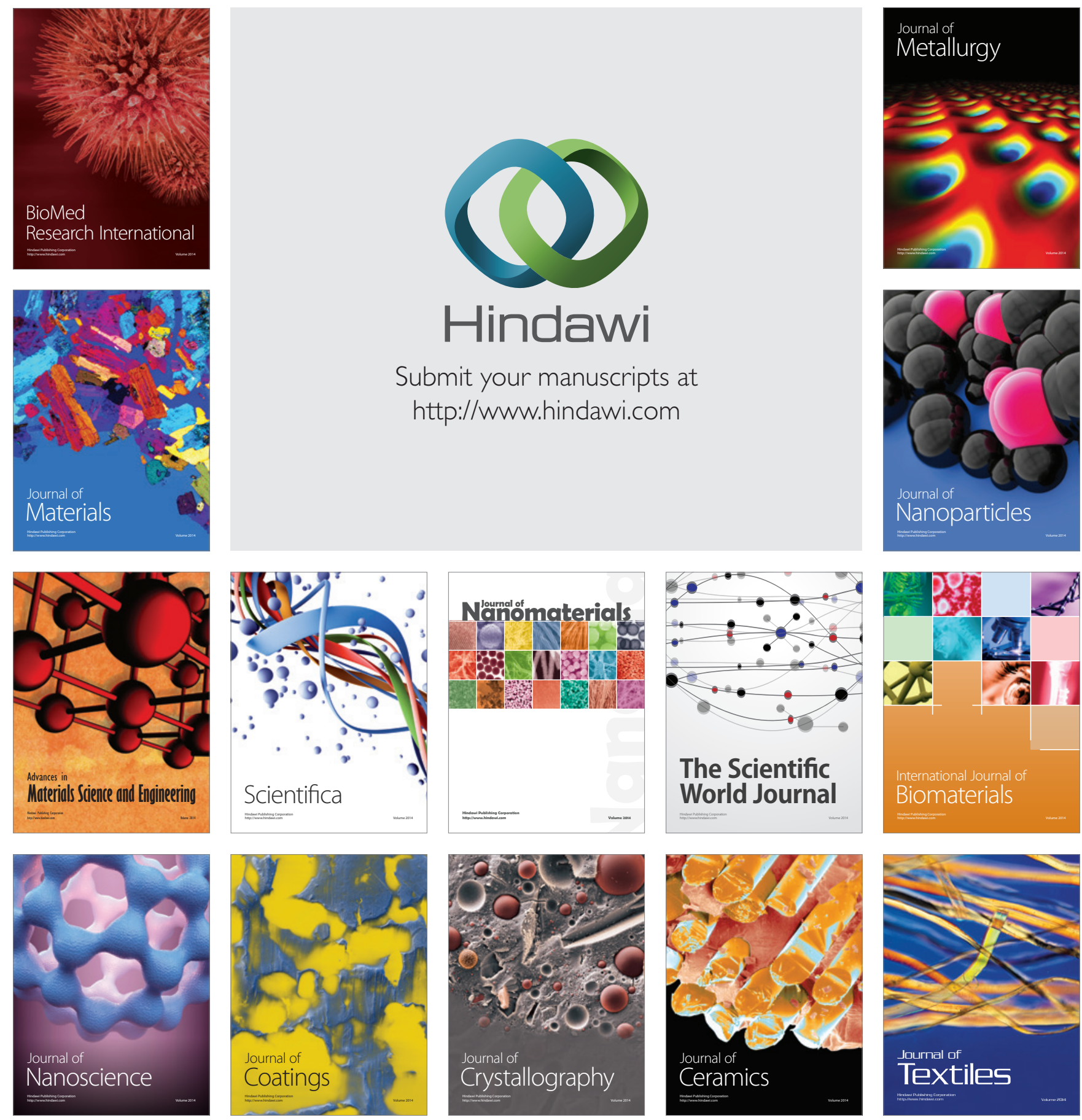